\title{
6 Social Roles of Digital Libraries
}

Karen Calhoun

Cornell University Library (retired)

ksc10@cornell.edu

Note: This is a preprint of a chapter whose final and definitive form was co-published in Exploring Digital Libraries: Foundations, Practice, Prospects by Facet Publishing (2014) and ALA Neal-Schuman (2014).

\section{Overview}

This chapter examines the social value of digital libraries. It begins by exploring past and present understandings of the value of libraries to their communities. Taking a well-known framework that lays out libraries' social roles as a starting point, the chapter then suggests a possible new framework to describe the social roles of digital libraries. The remainder of the chapter explicates this potential framework, exploring aspects of each social role. The sections offer examples, consider benefits and challenges, and draw attention to key readings from digital library researchers and practitioners.

\section{Introduction}

This chapter treats aspects of the topic of the value of digital libraries to society. With respect to the concept map from chapter 3 , this chapter deals with the lower right quadrant-that is, the intersection of the communities that use digital libraries and their social and economic aspects. In a nutshell, the following sections center on social roles and how digital libraries might:

- Support the free flow of ideas

- Empower individuals

- Support teaching, learning and the advancement of knowledge

- Provide economic benefits

- Preserve intellectual and cultural assets for future generations

Keywords: Libraries and community; Digital libraries-Aims and objectives; Information society; Libraries and the Internet; Digital divide; Digital preservation 
The approach to these questions can be informed by a brief look into how libraries' social roles have evolved in general. The leaders of the $18^{\text {th }}$ century French and American Revolutions, influenced as they were by classical ideals of free inquiry, the pursuit of enlightenment and the concepts of deism (as articulated, for example, in Thomas Paine's Age of Reason), tended to define libraries in terms of their social roles supporting knowledge, literacy and the principles of a free society. Olivier Fressard (2008) offers a French perspective on these issues.

The inscription quoting James Madison, the framer of the US constitution and Bill of Rights, on the front entrance to the Library of Congress Madison Building is an example of their perspective: "Knowledge will forever govern ignorance: and a people who mean to be their own governours must arm themselves with the power which knowledge gives." These core assumptions about the societal roles of libraries were a factor in the development of strong public library systems, mission-driven national libraries and well-funded college and university libraries in democratic societies around the world.

As discussed in previous chapters, for many years conventional thinking has tended to emphasize the collections of libraries over their societal or community-based roles. Many perceive libraries as collections of things (especially books), or tend to place information processes (selecting, collecting, organizing, preserving, providing access to information) at the center of how they define libraries. Yet when David Lankes and colleagues (2007) describe the library as a "facilitator of conversations" they are bringing forward—and reframing for the digital age-equally important assumptions underlying the perception of libraries as trusted social institutions that are vital to democracies, open inquiry and the advancement of knowledge and culture. 
McClure and Jaeger $(2009,15-17)$ have been studying the changing roles of public libraries in the US. They trace the development of the social position of the library as a "marketplace of ideas" from the 1930s forward, when public libraries in the US began to consistently assert the importance of equal access to diverse information for all citizens. In the UK, Bob Usherwood, a leading library scholar, devoted much of his long career to research on the social roles of libraries and other cultural institutions (Corrall 2013). In the process, Usherwood developed and applied innovative qualitative methods such as "social audits" to get beyond the numbers and focus on the outcomes that public libraries produce (Usherwood 2002b). Outcomes-based methods like Usherwood's are now being used to evaluate the impact of academic libraries in US higher education, in particular how libraries contribute to research, the advancement of knowledge and student success (see Oakleaf 2010, Association of College and Research Libraries 2011).

Jaeger (2010) is one of many who have commented on the resurgence of attention to the societal value of public libraries that has been spurred by the economic crisis of recent years. Also recently, Bas Savenije (2011), director general of the national library of the Netherlands, has offered helpful detail on the societal role of libraries in that country.

In earlier work on the social roles of libraries, McClure (1987) laid out a framework, since updated several times in light of the internet's impact, describing US public libraries' community roles as:

- Centers for activities, information, research, reference and independent learning

- Providers of educational support

- Providers of resources targeted to specific age groups or interests 
Usherwood's research results (2002a) suggest that UK public libraries have positive impacts on both individuals and communities in terms of:

- Personal development and education

- Social cohesion

- Community empowerment

- Local culture and identity

- Imagination and creativity

- Health and well-being

McClure's framework and Usherwood's findings cast library roles in terms of direct social involvement in the community to be served. They capture what a library can accomplish, for whom, and for what community benefits. The outcomes-based approaches exemplified by McClure and Usherwood's work are extremely useful and liberating in that they shift attention away from an information-processing or collection-centric definition of libraries toward a community-centric definition. This shift of focus enables new ways to think about services, space, expectations and potential not just for libraries but also for digital libraries in the networked environment.

Taking the McClure framework as a jumping off point, I analyzed the findings of digital library researchers and practitioners to tease out insights and results related to how digital libraries contribute, have contributed, or could contribute value to the communities they serve. The result was the construction of a potential service framework for digital libraries' social roles. The remainder of this chapter describes the background and aspects of this potential framework. 


\section{Foundations of digital libraries' social roles}

As has been noted earlier in this book, the initial US call for digital library proposals (DLI-1) focused mainly on achieving technological advances, extending existing information retrieval systems, and gathering digital content, with less attention accorded to the social, behavioral and economic aspects of digital libraries (NSF 1993). Notwithstanding the call's technical focus, the source documents leading up to DLI-1 reveal many rich conversations and thoughtful deliberations around the potential social roles of digital libraries. This author perused and analyzed the original white paper, several workshop summaries, and many participant observations in the 441-page Source Book on Digital Libraries, which contains various working papers from NSF-sponsored activities that led to the DLI-1 call for proposals (Fox 1993b). The effort revealed some convergence around the notions that digital libraries would advance science, technology and education by creating an "intellectual infrastructure" for:

- Supporting rapid delivery and exchange of new research results and innovations (that is, establishing a scholarly "marketplace of ideas" on the network)

- Helping to make sense of the ever-increasing volume of information

- Significantly increasing the productivity of scientists, engineers, educators, students, and those working in the commercial sector

- Providing easy recognition and re-use of earlier research results (thus reducing duplication of effort)

- Underpinning further discoveries and innovations

- Speeding technology transfer

- Stimulating the development of computer-based training and distance learning

- Supporting self-education

- Improving scientific and engineering teaching and learning in general 
- Fostering and enhancing collaboration and partnerships among and across individuals, institutions, groups, and domains (education, research, commerce)

- Broadening access to high quality information for all

Given these hopes for the roles that digital libraries would play, and their resonance with several elements of McClure's framework for the social roles of libraries, it is perhaps not surprising that Fox's conclusion for the Source Book (1993b, 394) pairs his sketch of the purpose of a US national digital libraries initiative with a reference to Thomas Jefferson's ideals:

Purpose: To advance US science and engineering efforts, particularly research, education and technology transfer, by improving the availability and supporting technology for access to useful information.

Note: We launch this in 1993 , the $250^{\text {th }}$ anniversary of the birth of Thomas Jefferson, who insisted that the free and vigorous pursuit of knowledge was essential to a democracy.

\section{Social Aspects of Digital Libraries Workshop 1996}

Pieces of the social agenda for digital libraries were taken up again in 1996, when the NSF funded an invitational "Social Aspects of Digital Libraries Workshop" (Borgman 1996). The workshop sought to uncover existing knowledge and propose a research agenda to develop new understandings of how digital libraries might support the professional, educational and recreational activities of diverse communities.

Christine Borgman, a key organizer and contributor to the 1996 NSF-funded workshop, has noted that the challenge for the information age will not be a choice between libraries and the internet, but "how best to provide access to information and how best to support the marketplace of ideas" and an informed citizenry in democratic societies (2000, 169-170). 
Borgman wrote confidently of the potential of digital libraries to enhance access, support learning, and promote the progress of knowledge, and with concern about balancing the broadest possible access with the rights of creators.

\section{Digital divide}

For the purpose of this book, the digital divide is the gap between those with and without access to digital information and ICT (information and communication technologies). Anaraki and Heidari $(2010,287-289,304-305)$ examine the dimensions of the digital divide in developing countries and the potential role of digital libraries in diminishing it. Savenije (2010a) points out that the digital divide exists not just in developing countries, but within countries where only some privileged organizations have ready access to licensed scholarly content. Along these lines, Creaser comments on the difficulties of providing for access to scholarly outputs to external users of research libraries $(2011,59-64)$.

Countless writers have made the case for open access to digital libraries of all kinds as a means to bridge the digital divide. Craven (2011) focuses on the issues of providing equal access to information for all and points out that the EC has given high priority to "e-inclusion" in its i2010 initiative. To a degree, the e-inclusion priority is driving EC investment in digitization, open access and digital preservation.

Noting that "the 'mobile library' of the future may in reality be a library service accessed by a mobile phone," Harle and Tarrant $(2011,132)$ make a case for librarians to engage and contribute their expertise to developing new mobile and online information environments for the disadvantaged. Liew $(2012,99)$ identifies steps toward more socially inclusive digital libraries that can enrich and empower individuals and communities, but emphasizes that digital libraries "will not do so by simply existing" and "mere digitization ... does not necessarily lead to social 
inclusion." Liew's article, well worth consulting, lays out the special requirements for moving more people across the digital divide and enumerates a number of ways the digital library community can or has contributed to progress.

\section{A possible framework of social roles}

As of this writing, not many sources explicitly and directly frame digital libraries in terms of their social roles. When authors have considered the social aspects of digital libraries, often it is in the context of user-centered design, work practice studies, the social web and other topics related to specific projects or programs.

As Van House $(2003,271)$ has pointed out, a theoretical or conceptual base for the social aspects of digital libraries has been lacking. Lavoie, Henry and Dempsey (2006) have noted the lack of a shared view in librarianship and the absence of a unifying framework to stitch individual digital library projects into a meaningful whole. A notable exception is Tanner and Deegan's 2010 report for JISC on the value of digitized resources. This report includes a well-argued case for digitization work, a wealth of useful and practical examples, a five-part model for digitization impact assessment, and a helpful section on methods for approaching the evaluation of intangible assets like digitized cultural content (e.g., the balanced scorecard).

As the discipline and practice of digital libraries is still relatively young, it is understandable that relatively little material addresses digital libraries' value to society. There simply has not been time for a shared understanding or theory of digital libraries as socio-technical systems to evolve.

This section proposes a tentative framework of digital libraries' social roles based on an analysis of that portion of the digital library literature that frames digital libraries in terms of their societal 
value. The framework's purpose is to make some sense of the many separate and seemingly disjointed themes in the digital library literature. The framework is intended to cover digital libraries of two broad types: digital libraries of cultural heritage content and digital libraries that support scholarly knowledge work.

It is important to be clear up front that I make no claims that the world's digital libraries, taken as a whole, presently deliver these aspects of social value; what is offered is a possible conceptual framework for examining their social roles. The framework could be used to spur further discussion of the social roles of digital libraries; spark the development of a better framework; provide a tool for assessment; or it could provide a jumping off point for a variety of planning tasks such as analyzing strategic options, considering priorities, or preparing targeted communications.

Figure 6.1 frames ten potential aspects of digital libraries' social value. The aspects are arranged in relation to one another and as a kind of flow or feedback loop. This arrangement is intended to illustrate how one social role can build on or reinforce another. There is nothing more intended in the way the social roles are arranged; other analysts may have ordered the roles differently than I did, or for that matter altered the roles themselves. Table 6.1, which follows the figure, provides some examples of each social role in context, in addition to some community benefits delivered as a result of this aspect of digital libraries' social roles. The subsections that follow the table offer a variety of perspectives on particular roles with the intent of further explicating what is meant by the content in the figure and table. 


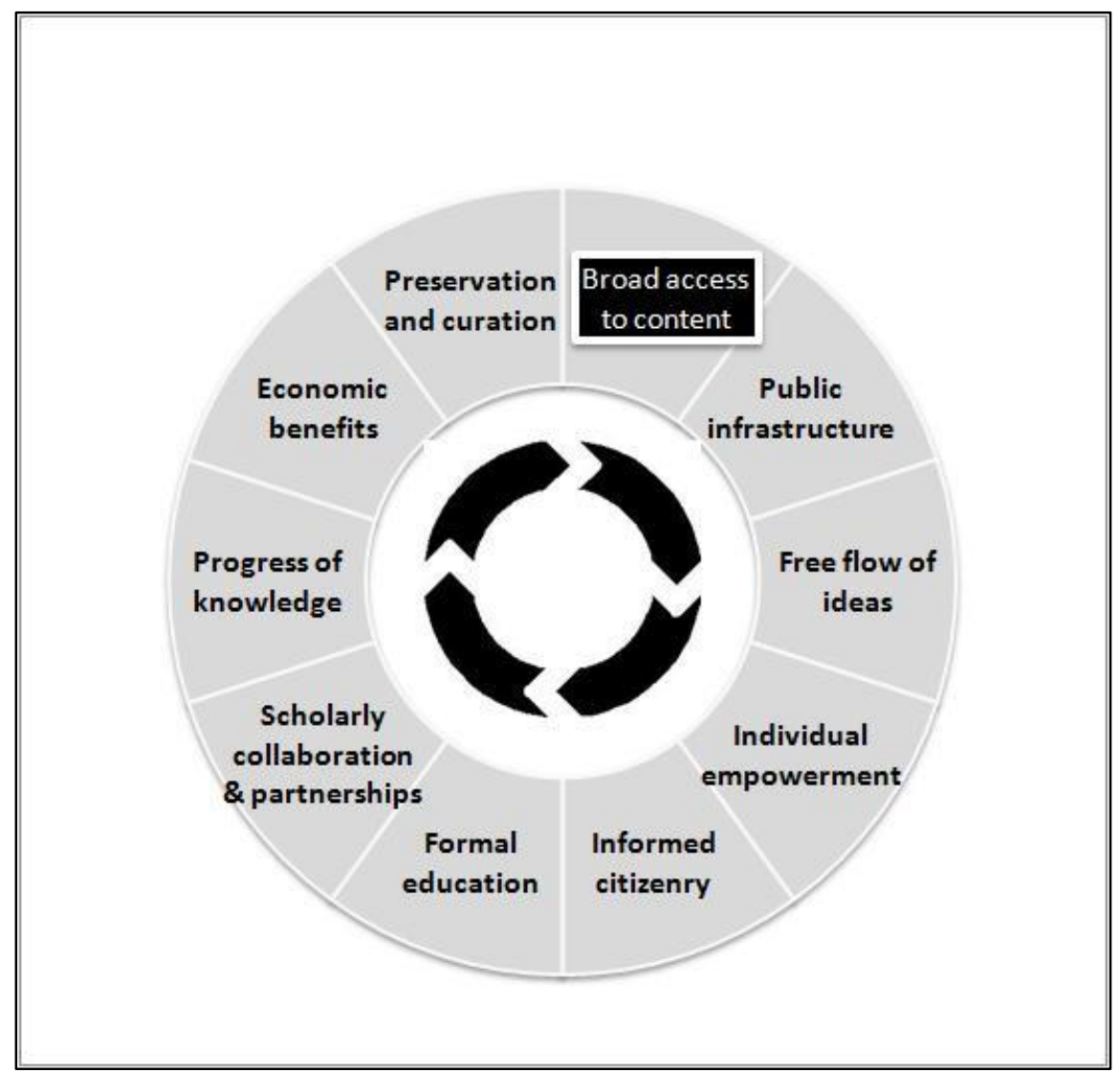

Figure 6.1 A framework of social roles of digital libraries 
Table 6.1 Potential Social Contributions of Digital Libraries

\begin{tabular}{|c|c|c|}
\hline Contributions & $\begin{array}{l}\text { Examples of services to offer or } \\
\text { engage with }\end{array}$ & Community benefits \\
\hline Broad Access to Content & $\begin{array}{l}\text { - International, national, } \\
\text { regional, or local heritage } \\
\text { digital libraries with historic } \\
\text { content, images, maps, } \\
\text { music, archives and more } \\
\text { - } \quad \text { Subject-based repositories } \\
\text { - Institutional repositories } \\
\text { - } \quad \text { Digital libraries supporting } \\
\text { teaching and learning for } \\
\text { specific groups } \\
\text { - Genre, format, or audience- } \\
\text { based digital libraries }\end{array}$ & $\begin{array}{l}\text { - Allow more content to be } \\
\text { collected } \\
\text { - Allow more access for more } \\
\text { people in more places or } \\
\text { contexts } \\
\text { - Balance between open } \\
\text { access for all and rights of } \\
\text { creators and providers of } \\
\text { content } \\
\text { - Make information mobile } \\
\text { - Enhance appreciation and } \\
\text { - engagement with culture } \\
\text { - Enable full participation in a } \\
\text { democratic society }\end{array}$ \\
\hline Infrastructure component & 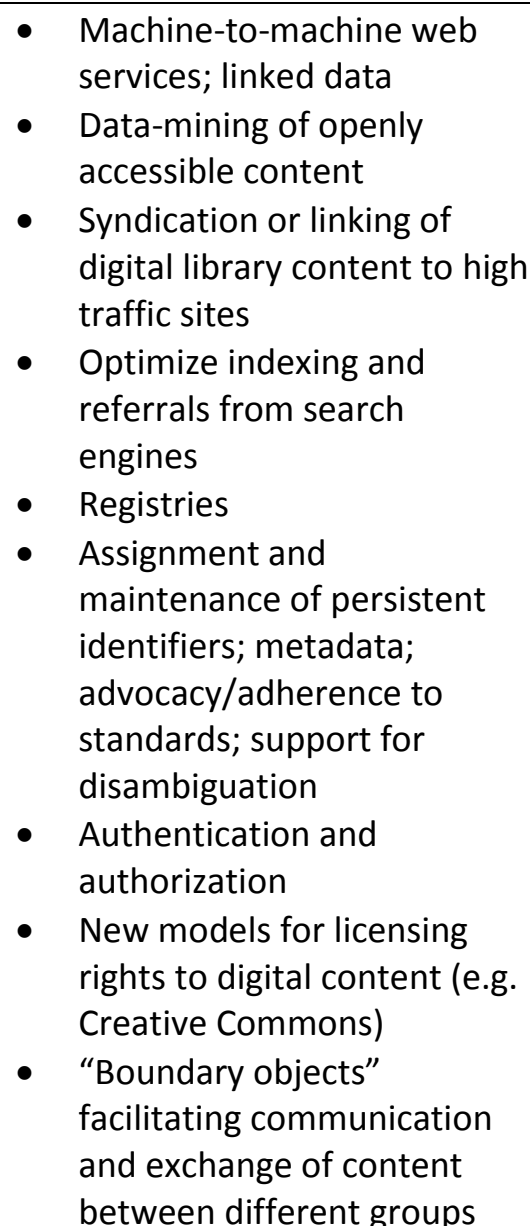 & $\begin{array}{l}\text { - Fundamental component of } \\
\text { the public information } \\
\text { infrastructure by enabling } \\
\text { the creation, deposit, } \\
\text { dissemination and } \\
\text { preservation of trusted } \\
\text { information } \\
\text { - Support information } \\
\text { exchange and re-use } \\
\text { (machine to machine and } \\
\text { person to person) } \\
\text { Help to make sense of an } \\
\text { increasing volume of } \\
\text { information }\end{array}$ \\
\hline
\end{tabular}




\begin{tabular}{|c|c|c|}
\hline Contributions & $\begin{array}{l}\text { Examples of services to offer or } \\
\text { engage with }\end{array}$ & Community benefits \\
\hline Free Flow of Ideas & 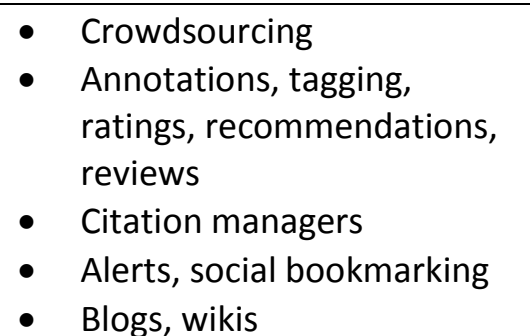 & $\begin{array}{l}\text { - } \quad \text { Be a locus of shared work } \\
\text { - Provide virtual space for } \\
\text { "rational and enlightened } \\
\text { discourse" } \\
\text { - } \quad \text { Facilitate interaction - } \\
\text { content, creators, the public }\end{array}$ \\
\hline $\begin{array}{l}\text { Individual Empowerment and } \\
\text { an Informed Citizenry }\end{array}$ & $\begin{array}{ll}\text { - } & \text { Virtual public libraries } \\
\text { - } & \text { Citabilion interfaces } \\
\text { - } & \text { services } \\
\text { - } & \text { } \text { Oggregatontent } \\
\text { - Online archives } \\
\text { - Online exhibits } \\
\text { - } \\
\text { - Onlinital reference information literacy } \\
\text { - } \text { instruction/tutorials/games } \\
\text { netwagement with social } \\
\text { nersonal profiling services }\end{array}$ & 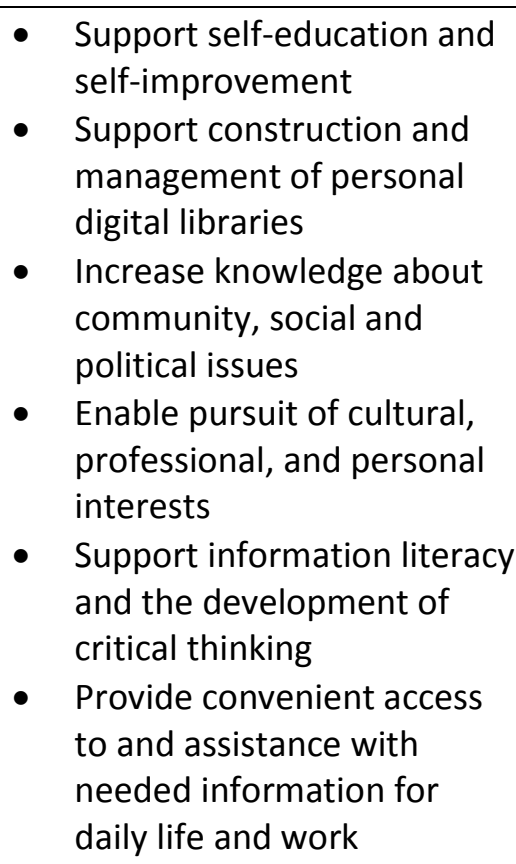 \\
\hline Formal Education & $\begin{array}{l}\text { - } \text { Educational digital libraries } \\
\text { - } \quad \text { Portals for teachers or } \\
\text { - } \text { students } \\
\text { - Integration with learning } \\
\text { - } \text { management systems } \\
\text { Access to primary sources }\end{array}$ & $\begin{array}{l}\text { - Improve teaching and } \\
\text { learning } \\
\text { - Support online teaching and } \\
\text { learning environments }\end{array}$ \\
\hline
\end{tabular}




\begin{tabular}{|c|c|c|}
\hline Contributions & $\begin{array}{l}\text { Examples of services to offer or } \\
\text { engage with }\end{array}$ & Community benefits \\
\hline Progress of knowledge & 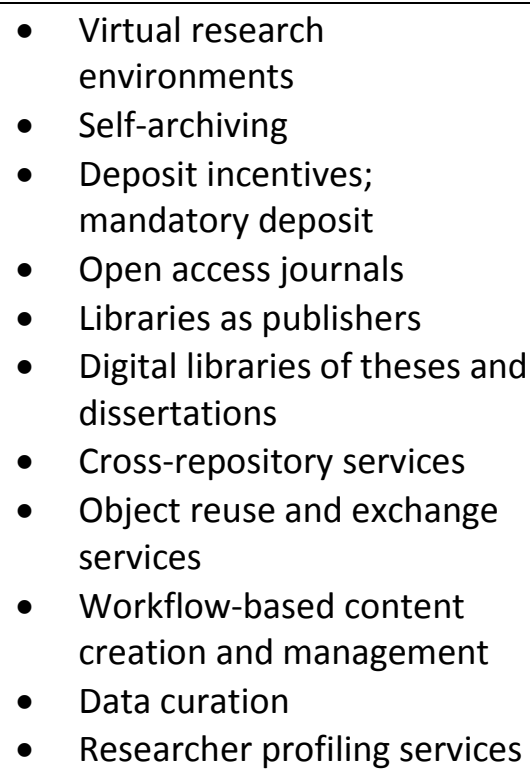 & 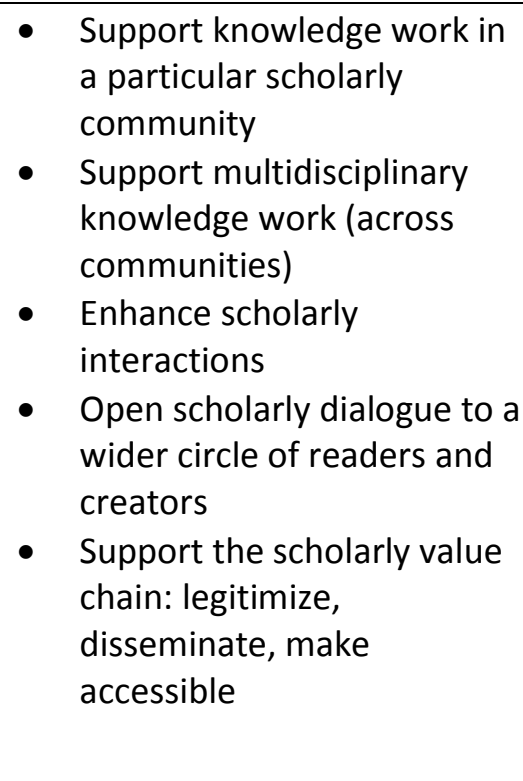 \\
\hline Economic Benefits & $\begin{array}{l}\text { Digital libraries that bring } \\
\text { scattered technical content } \\
\text { together, creating } \\
\text { efficiencies and saving } \\
\text { researcher time (e.g. see } \\
\text { Kurtz and others } 2005 \text { on } \\
\text { NASA digital library) } \\
\text { Digital libraries of cultural } \\
\text { heritage content (by } \\
\text { attracting attention, } \\
\text { spending and investment) } \\
\text { New products, processes, } \\
\text { services and economic } \\
\text { development spurred by } \\
\text { access to digital libraries }\end{array}$ & $\begin{array}{l}\text { - Support efficient and rapid } \\
\text { access to intellectual and } \\
\text { cultural assets } \\
\text { - Provide rapid and easy } \\
\text { recognition and re-use of } \\
\text { previous results (reducing } \\
\text { duplication of effort, raising } \\
\text { quality) } \\
\text { - Increase the productivity of } \\
\text { researchers, scholars, and } \\
\text { entrepreneurs } \\
\text { - Foster new discoveries and } \\
\text { innovations } \\
\text { - Speed } \\
\text { technology/knowledge } \\
\text { transfer }\end{array}$ \\
\hline
\end{tabular}




\begin{tabular}{|c|c|c|}
\hline Contributions & $\begin{array}{l}\text { Examples of services to offer or } \\
\text { engage with }\end{array}$ & Community benefits \\
\hline Preservation and Curation & 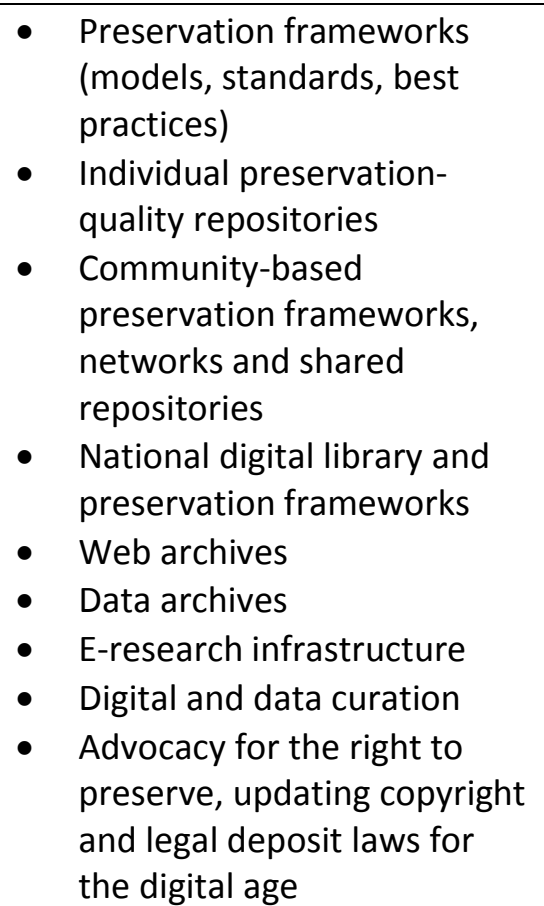 & $\begin{array}{l}\text { - } \begin{array}{l}\text { Preserve intellectual and } \\
\text { - }\end{array} \text { Proltural assets for future use } \\
\text { preservation } \\
\text { - } \quad \text { Registration of content and } \\
\text { data } \\
\text { - Stewardship and long term } \\
\text { access }\end{array}$ \\
\hline
\end{tabular}

\section{Broad access, infrastructure and the free flow of ideas}

Those who have responsibility for leading or funding national or other large-scale digital library initiatives tend to speak more directly than other writers to why digital libraries matter to society and the reasons to invest in them. Dame Lynn Brindley of the British Library, for example, wrote of digital libraries' role in facilitating research, formal and informal education and the free flow of ideas (Brindley 2009). She points to key challenges related to supporting long-term retention and re-use of a nation's intellectual assets; enabling collaboration; fostering information literacy and the development of critical thinking skills; enabling full participation in a democratic esociety; and balancing the values of open access with protecting intellectual property rights. 
The National Library of Australia (NLA) is known for its success establishing unified national programs to support public education, contribute to culture, and preserve heritage. Warwick Cathro $(1999,2001,2009 a, 2009 b)$ viewed the NLA"s digital library as a key component of the national information infrastructure, vital to carrying out the national library's stewardship role. He worked to address a number of key digital library challenges, for example, to establish web archiving of selected Australian sites; to digitize and preserve national heritage content, especially newspapers; and to advocate for extending legal deposit to digital publications and establishing reasonable access conditions for this content. Bas Savenije of the national library of the Netherlands has advocated tirelessly for open access, not only to cultural heritage materials in the public domain (Savenije and Beunen 2012), but also for the purpose of breaking down access barriers to all types of content, including scholarly publications (2010a, 2010b, 2011). He has argued that open access to digital libraries of cultural and scholarly content is good economic and social policy for today's knowledge societies, enabling full cultural participation and providing indispensable support for national and international infrastructures for research and education.

\section{Empowering and informing individuals}

Simon Tanner (2009) remarks on the potential for digital libraries to empower individuals, inform citizens and narrow the digital divide. He contends that a major function of digital libraries is to enhance appreciation and engagement with culture and the information society in general. Noting that more people are becoming wirelessly connected, and devices are becoming more mobile, He argues for digital library designers and developers to focus new efforts on greater interaction with users in the "ambient intelligent environment" that is emerging.

Digital libraries have demonstrated their value for empowering individuals in a number of ways. The evidence compiled by Davis (2011) suggests that open access publications reach more 
readers, especially readers outside the research community, thus increasing the diffusion of scientific knowledge to the public. Digital libraries can underpin not only independent learning, but also open community-based creation, contribution and aggregation of intellectual content. Aaron Krowne (2003), a co-founder of PlanetMath.org, writes of digital libraries as actionable collections of knowledge, built by and for a grass-roots community of users (a "commons").

Wikipedia and PlanetMath are similar in that they are community-sourced, open, socially shared knowledge spaces, but PlanetMath differs in that it was built using a digital library approach (and for a particular audience-those interested in mathematics, including all age groups and inside or outside a professional or formal settings). Successful commons-based digital libraries like PlanetMath become even more visible when they are harvested into OAI-based aggregations, crawled by search engines or made available to the semantic web; in all these ways they become more discoverable by ordinary citizens as well as specialist groups.

Neil Beagrie (2005) was one of the first in the digital libraries field to write in detail on the trend to a "more informal and increasingly empowered landscape of personal collection" on the web along with a shift from passive digital information consumption to more active creation, customization and sharing of digital content. Personal digital libraries containing individual digital objects as well as external content are not uncommon and they can form part of an individual's public persona on the web. In parallel with this trend, a number of online services and collaborations have emerged that further empower individuals to create, interact with, manage and share digital content-sometimes for purely personal reasons and sometimes to contribute to say, citizen science initiatives. Chapters 9 and 10 discuss citizen science and Krowne's and Beagrie's ideas in the context of the social web. 
Those building or maintaining digital libraries are increasingly responding to the personalization trend by embedding content in ways and where it can easily be consumed, shared, re-used and improved by individuals. "The Commons" on flickr.com is one of the examples discussed in chapter 10.

\section{Supporting teaching and learning}

The role of advancing formal education has been associated with digital libraries from the start. Fee-based digital libraries of articles and journals from well-known scholarly publishers were quickly taken up by the academic community when they began becoming available in the 1990s. Cultural heritage digital libraries organized by national libraries, like American Memory, Gallica and others, are well integrated into teaching and learning for all educational levels. Some subject, genre, or format-based digital libraries have become central to higher education in specific disciplines. Some broad-based digital libraries (the Internet Public Library for example: ipl.org) are frequently used by primary and secondary school teachers and students. As noted by Tanner and Deegan $(2010,17)$, because a large body of the UK's cultural assets have been digitized, courses can be enriched and whole new topics can be studied.

The take-up of other educational digital libraries has been less straightforward. Once initiatives to build educational digital libraries for specific disciplines or learning communities got underway, it became obvious that being successful would involve more than pulling the appropriate digital collections together and making them searchable (as difficult as that could be). A number of early projects found that the principle of "build it and they will come" is not a path to success. An important recognition has been that a educational digital library must be social—a meeting place or virtual lab for collaboration, overcoming isolation and engaging others; and it must be designed in alignment with teachers' or students' work practices and behaviors. Chapter 7 discusses these ideas further. 


\section{Scholarship, collaboration and the progress of knowledge}

Nancy Van House $(2003,271)$ writes of the importance of digital libraries to cognitive or knowledge work. Digital libraries not only provide or aggregate widely distributed content critical to this work; they enable new frameworks for the social aspects of creating and certifying new knowledge. These aspects include collaborating and learning together across time and space as well as the process of deciding what information, and which people and organizations to trust.

Contending that digital libraries are boundary objects (entities that link different communities together), Van House sees a digital library as "a locus of shared work" (287) for contributing content, using it, and participating in the digital library's creation and maintenance. She frames the digital library as "a heterogeneous network of users, researchers, funders, operators, and other people; of documents, images, databases, thesauri, and other information artifacts; of practices and understandings; and of technology" (289-290). Along these lines, and as discussed in chapter 1, the DELOS Digital Library Manifesto (Candela et al. 2006, 6) contains a collective vision of a digital library as "a tool at the centre of intellectual activity."

The complexities of the landscape of knowledge work are well documented by Harley and others (2010), whose findings from 160 interviews of scholars from seven disciplines suggest that the current social and economic structures and reward systems underpinning scholarly communications are firmly entrenched and represent significant barriers to innovation. Nevertheless, Harley's findings suggest that open access repositories (both discipline and institutionally based) are having positive impact, when taken as a whole. Among their benefits, open access repositories can enable rapid recognition (and credit) for new findings and offer a place to deposit and build awareness for conference presentations or working papers. In 
addition, through openly available pre- and post-prints they substantially broaden access to high-quality scholarly papers to larger, cross-disciplinary audiences.

\section{Economic benefits, innovations and technology transfer}

The digital libraries discipline has produced little literature that directly addresses the economic value of digital libraries as a whole. A great deal has been written about sustainability. There are in addition a number of cost-benefit analyses of various types of digital libraries; many articles on business models, particularly with respect to open access; and articles on the economics of digital preservation. Discussions of some of this body of literature can be found in chapter 7 . This section has a different starting point: it briefly addresses the question of the economic value of digital libraries to society. It makes use of some perspectives from microeconomics in that it touches on topics like the sources of economic health, innovation, value chains and the nature of markets.

It is generally recognized that the global economy is a "knowledge economy" or "knowledgebased economy" (see Cooke and Leydesdorff 2006 for a review of each phrase's development). In brief, a knowledge economy is driven by knowledge processes-the exploration, exploitation and examination of knowledge. In a knowledge economy, innovation and technology transfer are extremely important; these involve the efficient and effective transfer of new knowledge, technology or methods to those who can develop them into new products, processes or services, thus producing economic value. Castells (1996) is widely cited for his seminal work on how knowledge and networks spur innovation and economic growth. Within the library literature, Tanner and Deegan (2010) argue that the digital agenda and digital resources reduce the costs and quicken the pace of innovation, thereby increasing a nation's economic competitiveness. 
Raym Crow's position paper (2002) for the Scholarly Publishing and Academic Resources Coalition (SPARC) is notable for its analysis of how scholarly knowledge markets work. He makes the claim that open access to scholarly content (enabled by repositories) will produce value for the knowledge economy by positively disrupting and rebalancing the current market (scholars, academic institutions and their libraries, publishers and readers). He argues for a new "disaggregated" model for producing scholarly content—based on the existence of a global network of distributed, independent and open digital libraries of research materials—-that "unbundles the principal functions of scholarly communication, thus presenting the potential to realize market efficiencies." These market efficiencies include:

- Significantly expanding readership and availability of scholarly research (not just papers but also other types of content), thus reducing the digital divide

- Improving operations and competition in the scholarly value chain (registration, certification, awareness, archiving, rewarding), thus reducing publisher monopoly power and increasing innovation

- Increasing the likelihood that digital research material will be preserved for future generations

Tanner and Deegan (2010) make a strong case for the economic and social benefits of digitizing cultural treasures. Carla De Laurentis (2006) offers a surprising and fresh assessment of digital cultural heritage content as a potential driver of innovation and economic value in networked knowledge economies. Arguing that digital content is among the underpinnings of successful knowledge economies, De Laurentis goes on to make a case for the economic value that can be generated by digital cultural heritage content from memory institutions (libraries, archives, museums) if it is appropriately used as a resource in a "digital value chain." The concept of a digital value chain is generally applied in an e-commerce context, describing how a digital resource of some kind is packaged and prepared for distribution and consumption on the 
web. In the context of De Laurentis' article, a digital value chain refers to a process that integrates and exploits digital cultural heritage content and, through a process in which many organizations participate, creates new value in new settings, such as e-learning, entertainment, media and business applications (e.g., supporting tourism).

De Laurentis argues that to produce this new economic value, memory institutions must shift from relatively passive roles as knowledge repositories to active participants in content production, in the process creatively collaborating with many kinds of partners (broadcasters and other media organizations, advertisers, educational institutions, etc.). Her ideas recall (and scale up) the previously discussed efforts by cultural heritage organizations to create new value by embedding digital content in new settings on the web (e.g., the Flickr "Commons" discussed earlier). Similarly, her ideas are interesting to consider in light of Europeana's intention to contribute to economic growth in the EU through "long tail" effects (Verwayen et al. 2008, 3-4).

\section{Preservation of intellectual and cultural assets}

"The preservation and re-use of digital data and information forms both the cornerstone of future economic growth and development, and the foundation for the future of memory." Thus Seamus Ross, then a professor and digital curation specialist at the University of Glasgow, began his eloquent contribution to the large and substantial literature of digital preservation $(2000,2)$. Yet the amount of networked-based content (which Ross labeled "d-facts") is not only staggering; it also poses more challenges for preservation than content recorded in physical media ("artifacts"). D-facts are fragile, preservation requires active intervention, and unlike artifacts this type of content is unlikely to survive periods of neglect. Commitment to digital preservation is required so that new generations, like Isaac Newton in his time, can continue "standing on the shoulders of giants." Legislation like that founding the US National Digital Information Infrastructure and Preservation Program (NDIIPP) in 2000 was based on the 
realization that effective digital preservation could protect billions of dollars of investment in the nation's knowledge capital (NDIIPP 2011).

Digital libraries can and do contribute to ensuring the future of memory. However, inclusion in a digital library does not by itself preserve content. The extent to which digital libraries succeed in preserving content depends on how the organizations that manage them allocate resources to ongoing digital preservation practices, as suggested by Lavoie and Dempsey (2004). The following paragraphs offer a more detailed look at key social aspects of digital preservation of intellectual and cultural assets.

\section{From collecting to preserving}

Digital preservation is a subset of the endeavor known as "digital curation," which the UK's Digital Curation Centre describes as the active management and appraisal of digital information over its entire life cycle, from creation and active use to selection, transfer and preservation, access and re-use (Pennock 2007; Higgins 2008). Paul Conway (2010, 64-65) clarifies the distinction between collecting digital objects and preserving them: "Digitization for preservation creates valuable new digital products, whereas digital preservation protects the value of those products, regardless of whether the original source is a tangible artifact or data that were born and live digitally."

In the case of institutional and subject-based repositories, Hitchcock and others (2007) have pointed out that relying on repository software for preservation is insufficient, as is merely storing content (which may become unusable as technologies advance). Yakel and others (2008) report similar concerns. Instead, the claim to protect repository content over the long term must be backed up with formal programs and a preservation-quality technological framework. As an example, Shreeves and others (2006) describe how the IDEALS repository at 
the University of Illinois (ideals.illinois.edu) is fully engaged in integrating digital preservation systems and practices.

\section{Types of content}

What follows is the briefest of introductions to an extremely large body of literature, beginning with a gloss on some of the types of content that have been the focus of digital preservation efforts, provided in table 6.2. Each of these different types of content has a different preservation profile, requiring different action agendas and involving different players.

Table 6.2 Some brief notes on digital preservation of selected types of content

\begin{tabular}{|c|c|c|}
\hline Types & $\begin{array}{l}\text { Examples (a combination of } \\
\text { repositories and projects) }\end{array}$ & Selected references \\
\hline E-journals & $\begin{array}{ll}\text { - } & \text { LOCKSS, CLOCKSS } \\
\text { - } & \text { Portico } \\
\text { - } & \text { JSTOR }\end{array}$ & $\begin{array}{l}\text { Seadle offers helpful analyses } \\
\text { for licensed and open access } \\
\text { journals (2010, 2011). Manz } \\
\text { (2012) provides an overview of } \\
\text { the current situation in a } \\
\text { number of European countries. }\end{array}$ \\
\hline $\begin{array}{l}\text { Books in mass digitization } \\
\text { projects }\end{array}$ & $\begin{array}{ll}\text { - } & \text { HathiTrust } \\
-\quad \text { Dutch National Platform for } \\
\text { Digital Publications } \\
\text { (working name) }\end{array}$ & $\begin{array}{l}\text { Rieger 2008b; York 2010; } \\
\text { Christensen 2011; Janssen } 2011 \\
\text { (Netherlands) }\end{array}$ \\
\hline Web archiving & $\begin{array}{l}\text { - Internet Archive Wayback } \\
\text { Machine } \\
\text { - } \text { PANDORA Archive } \\
\text { - UK Web Archive }\end{array}$ & $\begin{array}{l}\text { Niu } 2012 \text { (overview of web } \\
\text { archiving); Toyoda and } \\
\text { Kitsuregawa } 2012 \text { (covers } \\
\text { Internet Archive, national and } \\
\text { university web archives); } \\
\text { Cathro, Webb and Whiting } 2001 \\
\text { (PANDORA); Bailey and } \\
\text { Thompson 2006; see also } \\
\text { webarchive.org.uk. }\end{array}$ \\
\hline Research data & $\begin{array}{l}\text { - UK Data Archive } \\
\text { - ICPSR (Inter-university } \\
\text { Consortium for } \\
\text { Political and Social } \\
\text { Research) } \\
\text { - } \quad \text { National Space Science Data } \\
\text { Center } \\
\text { - } \text { DataCite }\end{array}$ & $\begin{array}{l}\text { Gold (2007a, 2007b) provides ar } \\
\text { introduction to research data } \\
\text { for libraries. Beagrie, Lavoie and } \\
\text { Woollard's } 2010 \text { report for JISC } \\
\text { includes a helpful taxonomy of } \\
\text { the benefits of research data } \\
\text { preservation. DataCite is a } \\
\text { global registration agency for } \\
\text { research data (Brase 2009). }\end{array}$ \\
\hline
\end{tabular}




\section{The right to preserve}

Traditionally, libraries have had the responsibility and legal rights to preserve that part of the intellectual and cultural record that is represented in the physical collections they own. With the rise of massive networked information and an interlinked, online scholarly communications system underpinned by licensed content from publishers, responsibility for preservation has become diffuse, and the right to preserve has become unclear (Ayre and Muir 2004). Ensuring against loss of network-based content for future users has come to require a great deal more action and collaboration across a diverse set of players and stakeholders who create, produce, select, manage, use and preserve content. A number of these players have the rights to preserve (such as commercial scholarly publishers that own or control content) but lack incentives to do so.

\section{Community-based solutions}

Don Waters (2007) analyzes a number of approaches to dividing the labor among stakeholders and providing incentives for preserving the cultural and scholarly record "on which future scholarship and education so clearly depend." He offers insight into community-based solutions that not only generate the public good of preservation and produce savings, but also balance open access with the rights of creators and producers. The final report of the Blue Ribbon Task Force on Sustainable Digital Preservation and Access (BRTF 2010) treats these issues in detail and offers a set of recommendations for sustainable preservation strategies across a diffuse set of stakeholders. This report clarifies a variety of stakeholder roles and offers action agendas for each group (BRTF, under table 5.1). 


\section{Roles for individual libraries}

On behalf of ARL, Lars Meyer (2009) completed an analysis and report on how the networked digital environment is reshaping the core preservation functions of research libraries, both at the level of individual institutions and in the realm of collective action. Of particular interest to the managers of digital libraries is Meyer's illustration (2009, under figure 1) of the potential range of a research library's preservation activities and commitments, from local to collaborative. There continue to be digital preservation roles for individual digital libraries (for a practical approach to defining them see Oehlerts and Liu 2013). These roles require a heightened understanding of best practices for digitization and born digital content, what others are collecting and preserving, the rights to preserve, and the roles of partnerships within and outside their parent institutions. There are also many more opportunities for collective action to advance the digital preservation agenda. Walters and others (2009) discuss a number of examples of collective initiatives, including the frequently mentioned MetaArchive Cooperative (metaarchive.org), a private LOCKSS network and an NDIIPP partner, that supports cultural heritage repositories at over 50 institutions.

\section{Infrastructure}

Efforts to establish a digital preservation infrastructure and best practices are progressing; a useful source is McGovern and Skinner's compilation (2012). The OAIS (Open Archival Information System) reference model is gaining recognition and use in the field (see Lee 2010 for a brief introduction to OAIS). A growing number of important digital preservation programs are based on the OAIS model. TRAC (Trustworthy Repositories Audit \& Certification), managed by the US Center for Research Libraries and OCLC, is a framework for certifying trusted digital repositories (Dryden 2011 offers a succinct overview of TRAC and related standards and activities). Metadata specialists have added significantly to the store of knowledge required to capture the source of content and how it was created, how to open and read the content, terms 
of access, migration history and interrelationships with other software and records, and more (for more on digital preservation metadata see Guenther and Wolfe 2009).

\section{The public policy environment and legal frameworks}

A number of national libraries are carrying out or facilitating ambitious programs to preserve their nations' digital assets (a small sample includes National Library of Australia 2008; Archives New Zealand 2009; Janssen 2011; Ledoux 2012). Part of this work involves fostering a public policy environment that promotes digital preservation and long-term access. Digital preservation faces significant legal obstacles due to current copyright laws and limitations on the legal deposit of digital content. A key finding of an NDIIPP study was that current legal frameworks "discourage preservation best practices or even make them illegal" (NDIIPP 2011, 4).

Besek and others (2008) describe the situation for copyright law and digital preservation around the world. Their study found that many national legal frameworks prevent digital preservation actions such as making multiple copies and migrating digital content to new technological formats and media. They conclude with joint recommendations for updating copyright and legal deposit laws for the digital era and in the public interest (Besek et al. 110-111). They also specify roles for "preservation institutions" (libraries, archives and museums) that will enable them to carry forward past roles protecting intellectual and cultural assets for the future. In addition a number of writers have focused on how legal deposit for digital content can ensure long-term access to the greatest number while respecting intellectual property laws (see for example Stirling et al. 2012).

\section{Conclusion}

Descriptions and perceptions of digital libraries are most often centered on their collections. While collections are important, they are far from being the only way that that libraries and 
digital libraries bring value to the communities they serve. This chapter offers a potential framework for examining and articulating digital library value across a range of social roles. The framework may assist digital library managers with:

1. Describing digital libraries to external audiences (for example parent institutions or funding bodies) in ways likely to resonate with them

2. Selecting strategic priorities and improving service to the communities that digital libraries serve

3. Defining desired social outcomes and assessing digital libraries based on their community impacts

The pressure for greater accountability seems to be affecting all organizations that contribute to the welfare of the public; those building or maintaining libraries or digital libraries are not alone in this way. Fortunately, research and practice using outcomes-based assessment approaches in libraries are advancing. Usherwood was an early advocate and implementer of outcomebased approaches to evaluation (2002a; 2002b); other sources of ideas and methods are Oakleaf (2010; assessing social and financial impact in academic and other types of libraries); Lougee (2009; strategic impact); Koltay and Li (2010; impact measures); and Kaufman and Watstein (2008; return-on-investment, or ROI measures).

Greater clarity about the community value and positive impacts of digital libraries can also be achieved by looking into digital library success factors. What are the distinguishing characteristics of successful, sustainable digital libraries? How do digital libraries attract, build and support online communities? These are the subjects of the next chapter. 